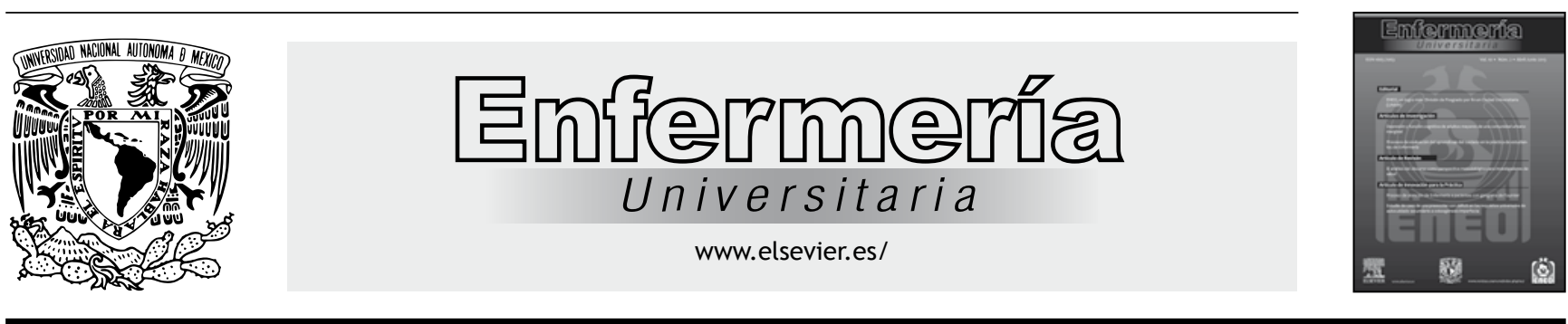

FE DE ERRORES

\title{
Fe de errores «Intervenciones de comunicación exitosas para el cuidado a la salud en personas con deficiencias auditivas»
}

\section{Erratum to the article "Successful communication health care interventions on persons with auditory impairments"}

En el artículo Intervenciones de comunicación exitosas para el cuidado a la salud en personas con deficiencias auditivas publicado en el número 4 del volumen 9 correspondiente al año 2012 páginas 57-68.

En autores Dice: PSS L.E.O. Nydia Loredo Martínez, Mtra. Reyna Matus Miranda* (*Profesora de Carrera TC Asociado ENEO UNAM)

Debe decir: PSS L.E.O. Nydia Loredo Martínez, Mtra. Rosa María Ostiguín Meléndez* (*Coordinadora del Programa de Maestría ENEO-UNAM) 